Anales de Historia del Arte

ISSN: 0214-6452

http://dx.doi.org/10.5209/ANHA.61600

\title{
Historias del arte en femenino
}

\section{Presentación}

\section{La nueva temporada de Anales de Historia del Arte}

La revista Anales de Historia del Arte da paso con este número de 2018 a una nueva etapa de su andadura, coincidiendo con el recientemente reestructurado Departamento de Historia del Arte de la Universidad Complutense de Madrid, en la que el nuevo equipo de redacción toma el relevo enfrentándose con ilusión a la tarea de publicar las reflexiones científicas más actuales en el terreno de la Historia del Arte y la Cultura Visual en un marco cronológico que abarca desde sus orígenes hasta la época presente, en un ámbito tanto nacional como internacional ofreciendo a las investigadoras e investigadores de universidades españolas y extranjeras un espacio donde dar a conocer tanto los resultados de sus trabajos, como un soporte para enmarcar el arte en los debates abiertos en el contexto de los retos sociales del mundo contemporáneo y donde plantear, desde una perspectiva académica, las controversias sobre los problemas de la especulación teórica, la conservación del patrimonio, los debates de género, la educación estética y ética, así como las grandes cuestiones que el mundo globalizado ofrece en torno a las nuevas perspectivas transculturales e interdisciplinares en el ámbito histórico artístico.

Hemos querido en este primer número que se realiza enteramente a cargo del equipo entrante empezar dando visibilidad a las cuestiones de género, temas desde hace tiempo tratados con rigor por muchas de nuestros especialistas, pero que solo muy recientemente parecen empezar a abrirse el espacio que merecen en el ámbito universitario. Historias del arte en femenino es una apuesta por el debate académico en torno a la pluralidad de perspectivas sobre las cuestiones que la presencia de la mujer, el debate feminista y lo femenino plantean en la Historia del Arte, si es que se puede hablar, desde esta perspectiva, de una sola Historia del Arte, pues con el título de nuestro monográfico proponemos también la ocasión de pensar o cuestionar las posibilidades de varias historias del arte paralelas, cruzadas o simultáneas. Imaginar la infinidad de oportunidades que esta controversia abre es el horizonte en el que la ciencia misma se mueve y en el que consideramos que la discusión intelectual y el diálogo constructivo y fértil dará sus frutos para seguir trabajando en nuestra disciplina. Este es el debate transversal y abierto, en el que esperamos que la pluralidad de enfoques enriquezca el enfoque que pretendemos proponer para todos y cada uno de los números monográficos de la revista que a partir de ahora se publicarán anualmente. 


\section{Historias del arte en femenino}

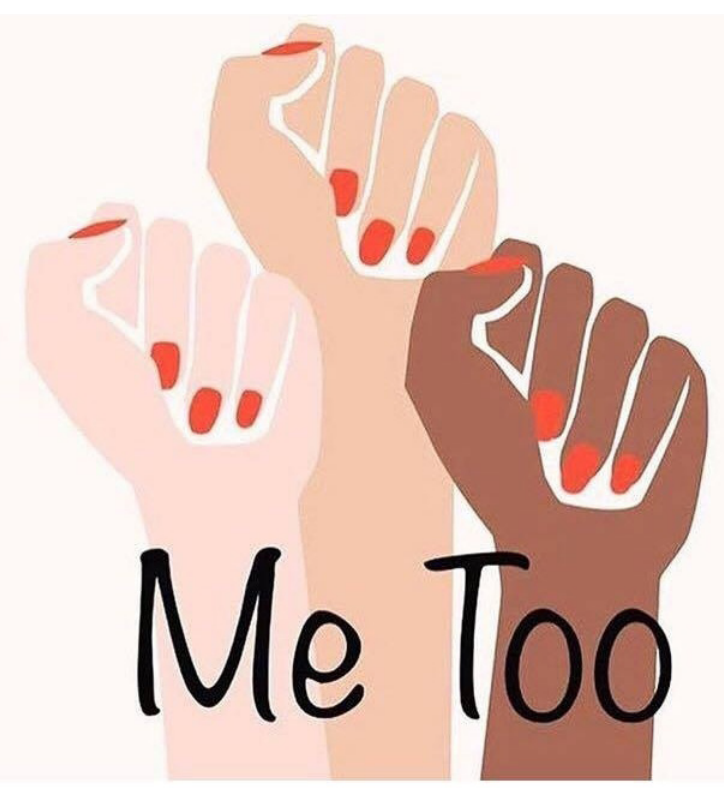

Cuando hace ya más de dos años lanzamos el call for papers para este número de la revista no imaginábamos que 2017 y 2018 iban a ser dos años absolutamente decisivos para el feminismo. 2017 fue el año del \#MeToo, ("yo también") nombre del movimiento para denunciar acosos y agresiones sexuales que se hizo viral después de las acusaciones formuladas contra el productor de cine Harvey Weinstein y que se extendió a través de este hastag, en el que hoy han participado cientos de miles de mujeres. Nada más iniciarse 2018, en la ceremonia de entrega de los Globos de Oro del cine americano muchas actrices optaron, por primera vez en la historia por ir acompañadas de mujeres normales y por activistas feministas, en lugar de acudir de la mano de sus vistosas y glamorosas parejas habituales, y la actriz y famosísima presentadora de televisión Oprah Winfrey en un discurso que fue visto por millones de personas, escogió el nombre de una mujer también desconocida para el público, Recy Taylor, un ama de casa afroamericana que había sido violada por seis hombres blancos en 1944, y que acababa de morir a sus 98 años sin haber visto perseguidos a sus agresores, para protagonizar su alocución. Creo que este suceso es enormemente significativo por dos motivos; en primer lugar, porque desde el mundo del arte nunca se había producido una denuncia pública similar del acoso sexual; en segundo lugar, porque el movimiento al que representa, ya no es un acontecimiento blanco ni euro occidental, sino una denuncia que trasciende las fronteras y habla en nombre de las mujeres del planeta; una propuesta transnacional que ha hecho que las palabras de Oprah: "ese tiempo ha acabado. Ya basta" hayan resonado fuerte y con optimismo como un manifiesto que marca un antes y un después en la situación de desigualdad de las mujeres, y también del papel que el arte puede jugar en esta reivindicación. De hecho, esta no es más que una entre las muchas demostraciones públicas que se han realizado desde entonces en todos los rincones del mundo en defensa de la igualdad en las que un nuevo lema: la sororidad sin ningún tipo de límites identitarios, culturales o sociales se ha convertido en el arma más poderosa. Ejemplos de ello son la manifestación del día 8 de marzo de 2018 en Madrid, y las distintas demostraciones públicas que han tenido lugar en España contra los casos de violencia machista, que han movilizado a millones de personas. 


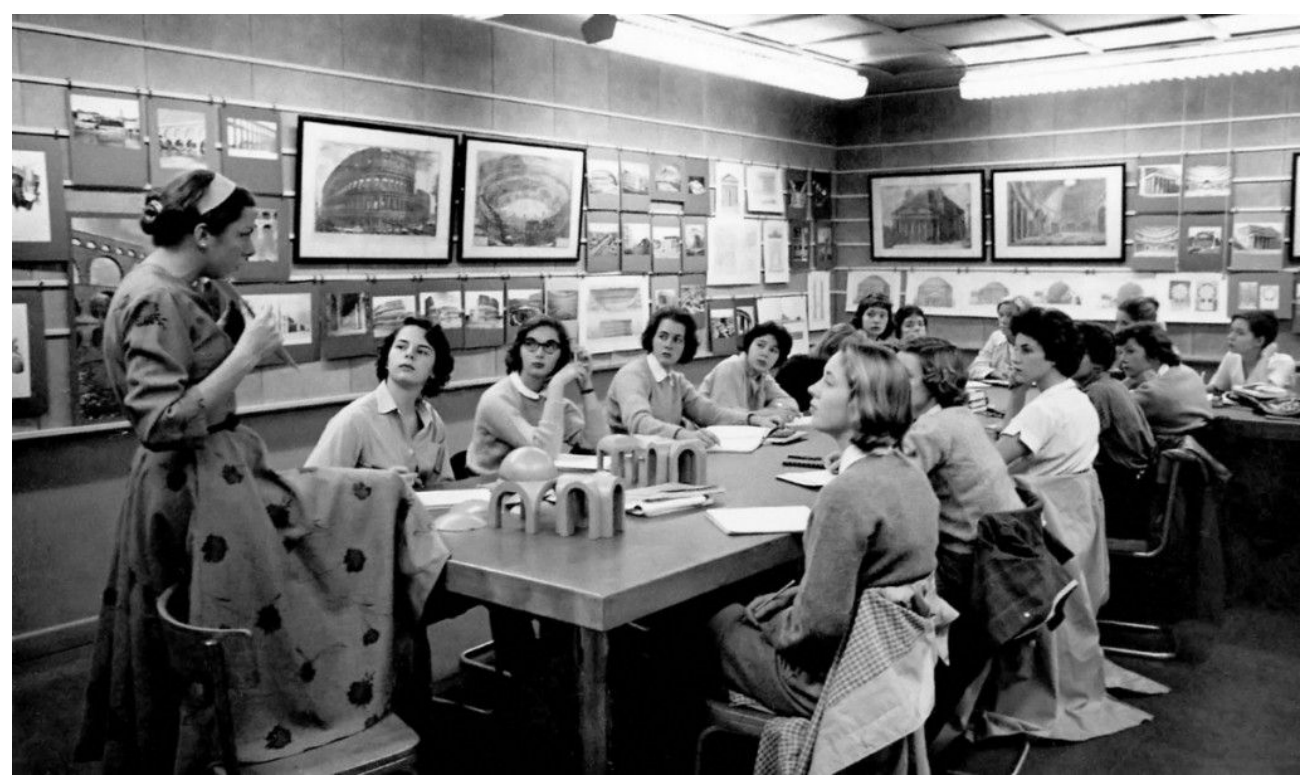

Linda Nochlin en los años 50 enseñando Historia del Arte en Vassar.

Cortesía Archives \& Special Collections Library, Vassar College

El mundo académico no ha permanecido en absoluto al margen de los retos que la sociedad demanda. 2017 fue un año importante también en el campo de la Historia del Arte en el ámbito internacional para el feminismo por la muerte de Linda Noclin, 2 la historiadora del arte pionera que con su famoso artículo de 1971 "Why Have There Been No Great Women Artists?", abría la caja de Pandora de las preguntas, debates, publicaciones y fértiles discusiones sobre arte y género, quizá uno de los debates críticos más vivos y con más consecuencias en los últimos años en el terreno de la Historia del Arte. Intentando contestar a la pregunta de Noclin ¿Por qué no ha habido grandes mujeres artistas? desde los años setenta se ha trabajado insistentemente en dar visibilidad a artistas olvidadas a lo largo de toda la historia; en España muchas colegas trabajan desde hace años en el entorno académico en este campo; entre ellas hay que agradecer el trabajo infatigable realizado en la Universidad Autónoma de Madrid por Rocío de la Villa y por Patricia Mayayo; en la Universidad Politécnica

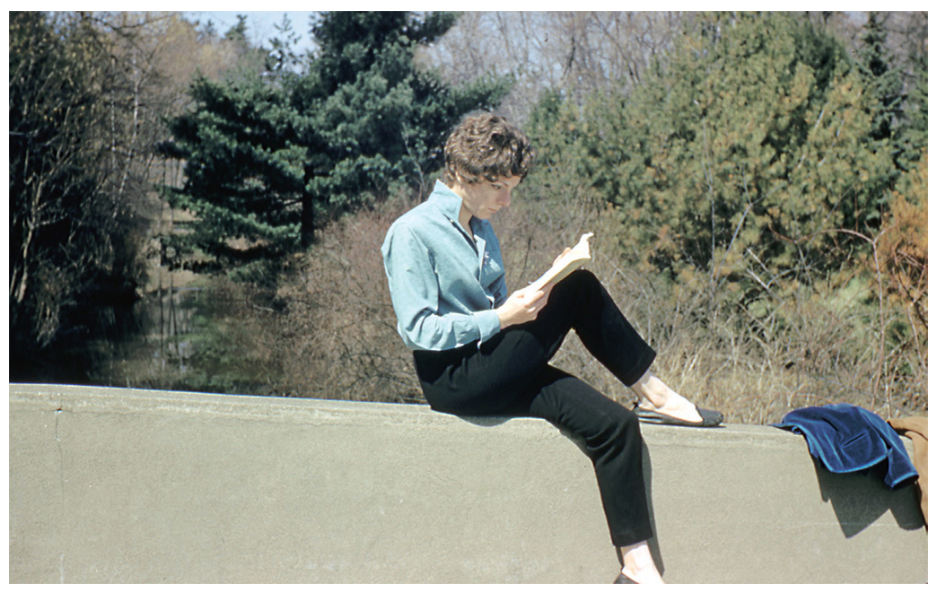

Linda Nochlin en el campus de Vassar en los años 60. Cortesía Archives \& Special Collections Library, Vassar College 
de Valencia por Juan Vicente Aliaga, en la Universidad de Barcelona por Erika de Bornay y por Assumpta Bassas; por Sagrario Aznar en la UNED, por Teresa Alarios en la Universidad de Valladolid, por Ana Martinez-Collado, en la Facultad de Bellas Artes de Cuenca. En la Universidad Complutense de Madrid contamos con la figurapionera, y con una de las pocas Académicas de Bellas Artes, de Estrella de Diego, con Beatriz Blasco Esquivias, con Marian López-Fernández Cao. Y estas no son más que unas cuantas personas entre las muchas que hoy trabajan desde la Universidad por dar respuesta a la pregunta de Nochlin. En estos años se ha creado la Plataforma Universitaria de Estudios Feministas y de Género, y muchas universidades españolas cuentan ya con unidades para la igualdad; a pesar de ello, la brecha entre hombres y mujeres ocupando cargos de responsabilidad en el mundo académico y en la investigación sigue siendo demasiado amplia, y la ausencia de estudios reglados sobre temas de género inexplicable.

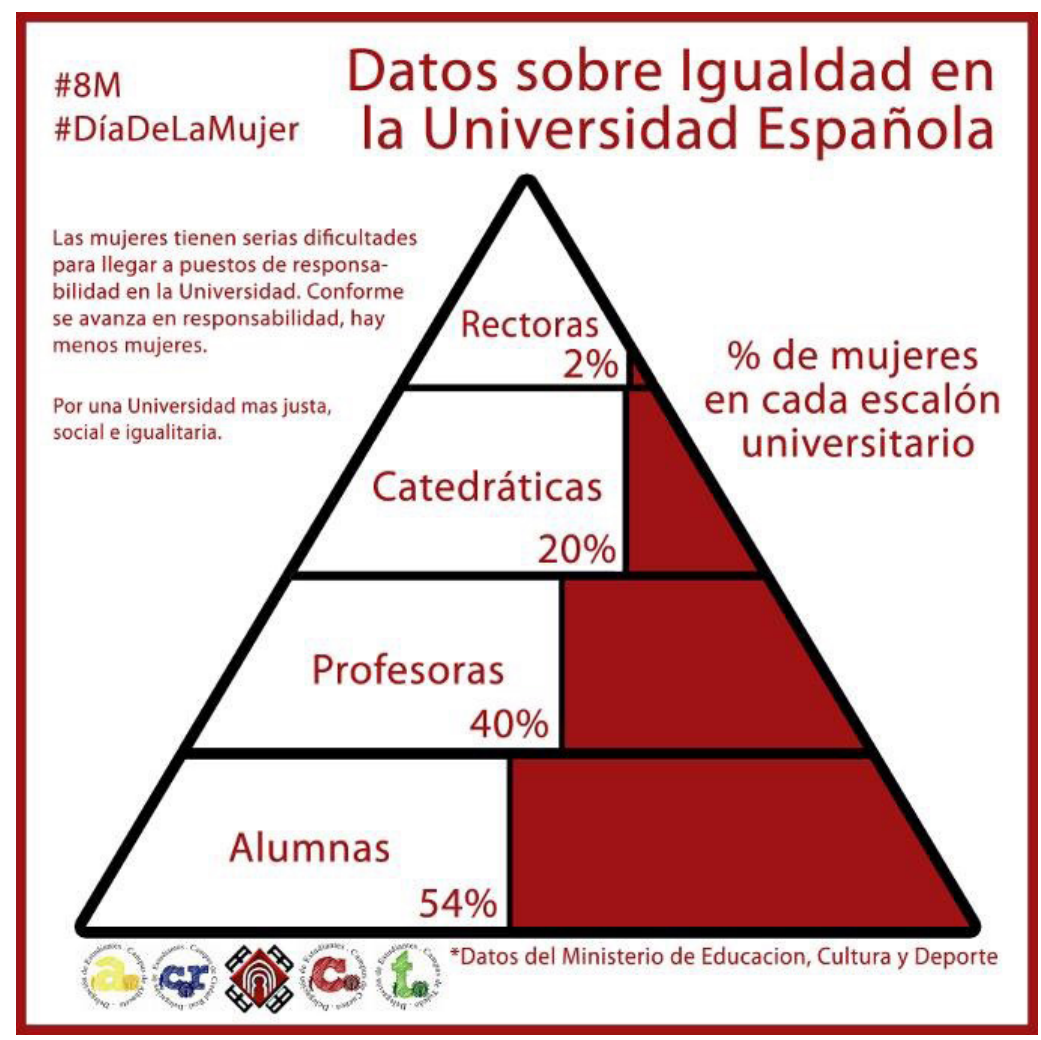

En el ámbito de los museos y exposiciones el panorama no es muy distinto, en el año 2016 el Museo del Prado expuso por primera vez en su historia la obra de una mujer, la de la pintora flamenca Clara Peeters, haciendo que muchas críticas volviesen a plantearse las cuestiones que los carteles de las Guerrilla Girls tantas ampollas levantaran en su momento: ¿es que las mujeres tenemos que estar desnudas para poder estar en los museos?.... ¿tendremos que conformarnos con todas las ventajas que reporta ser mujer artista en un mundo de hombres? 


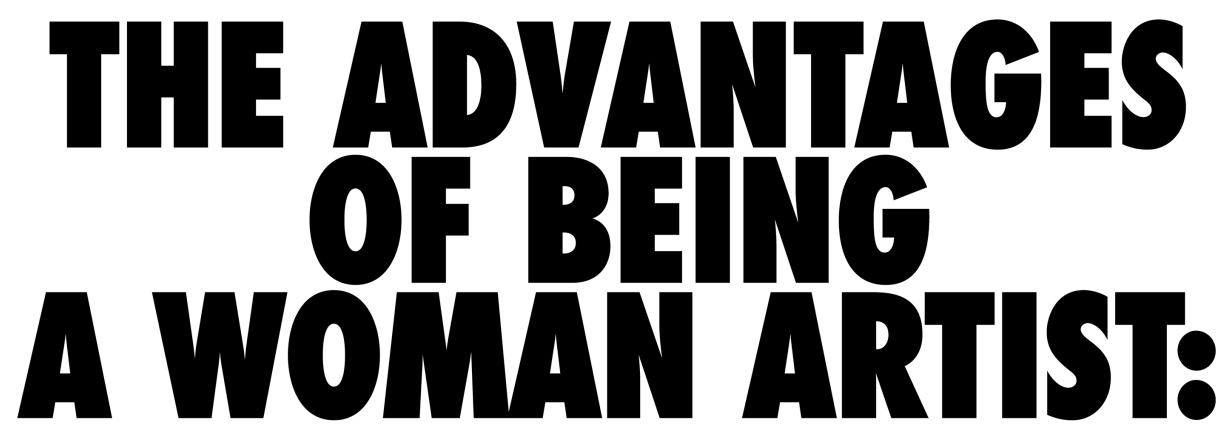

Working without the pressure of success Not having to be in shows with men Having an escape from the art world in your 4 free-lance jobs Knowing your career might pick up after you're eighty Being reassured that whatever kind of art you make it will be labeled feminine Not being stuck in a tenured teaching position Seeing your ideas live on in the work of others Having the opportunity to choose between career and motherhood Not having to choke on those big cigars or paint in Italian suits Having more time to work when your mate dumps you for someone younger Being included in revised versions of art history Not having to undergo the embarrassment of being called a genius Getting your picture in the art magazines wearing a gorilla suit

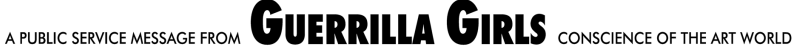

Guerrilla Girls, The Advantages of Being A Woman Artist, 1988 Copyright (C) Guerrilla Girls, courtesy guerrillagirls.com

La asociación MAV (Mujeres en las Artes Visuales) lucha desde su fundación por dar visibilidad al papel de la mujeres en estos ámbitos y la plataforma La Caja de Pandora ha conseguido aunar desde su creación en 2017 a más de 3000 mujeres vinculadas al mundo del arte. Muchas son las artistas que reivindican el papel de la mujer en el arte o el lugar que a estas les ha sido arrebatado en las ferias, exposiciones y museos: tres artistas formadas en la UCM, Yolanda Domínguez, María Gimeno y Diana Larrea han mostrado en estos años interesantísimos trabajos en este sentido. La primera con su performance Queridas Viejas, se propuso incluir, cuchillo en mano, a las artistas olvidadas en la Historia del Arte de Gombrich, la segunda, a lo largo de todo un año, desde Junio de 2017, realizó una acción en su muro de Facebook titulada "Tal día como hoy" en la que fue dando a conocer la obra y vida de mujeres artistas invisibilizadas. Yolanda Domínguez, entre sus muchos trabajos relacionados con los estereotipos de género y con el consumo, este año 2008 ha realizado \#Estamosaquí, una propuesta para visibilizar a las mujeres en el ámbito de la cultura, coincidiendo con la inauguración de ARCO 8, donde un año más, la cifra de mujeres españolas representadas era muy baja (de un $6 \%$, según datos recogidos por MAV). Se trata, sin duda, de datos sorprendentes, como lo es el hecho de que 7 de cada 10 premios sean para artistas hombres, cuando 6 de cada 10 estudiantes de Bellas Artes son mujeres. Según un estudio de la universidad de Luxemburgo, el arte de de mujeres se vende un $47 \%$ más barato que el realizado por hombres; es inexplicable tam- 


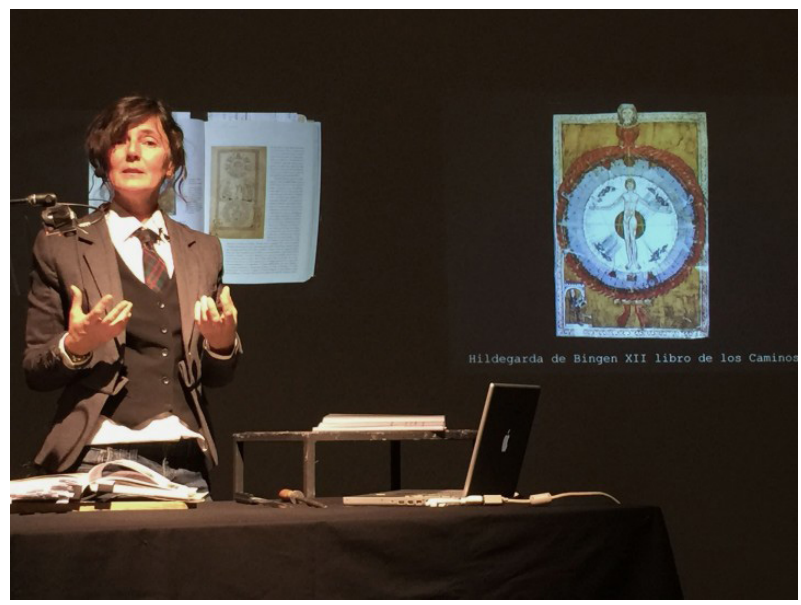

María Gimeno, Queridas Viejas. Editanto a Gombrich, 2017, Facultad de Bellas Artes, UCM. Cortesía de la artista.

bién que los grandes museos contemporáneos del mundo dediquen a las mujeres un porcentaje de exposiciones por debajo del 20\%. Estas cifras no se limitan al mundo de la creación: en España el 80\% de los cargos directivos de los museos son hombres y el número de investigadoras en el ámbito universitario con cargos de responsabilidad decrece también a medida que se asciende en la escala de responsabilidad, a pesar de que el número de alumnas mujeres es mayor que el de varones. No hay que olvidar el destacado papel desempeñado en en el esfuerzo por incluir a las mujeres artistas en el discurso histórico artistístico de comisarias independientes, como Susana Blas, o el de asociaciones como Blanco, Negro y Magenta, formada por treinta mujeres que se ocupan de dar visibilidad a las mujeres artistas, y denunciar la violencia machista y la injusticia a través de gran cantidad de actividades, entre las que destaca la publicación de su magnífica revista: https: //issuu.com/magentasweb/ docs/revista2low

Diana Larrea, Tal día como hoy, acción realizada en Facebook desde junio de 2017.

Cortesía de la artista.

Página siguiente: Yolanda Domínguez, acción \#Estamosaquí, 21 de febrero de 2018. Cortesía de Yolanda Domínguez y de las artistas participantes.

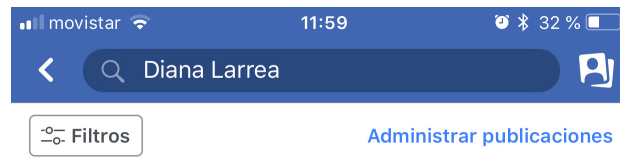

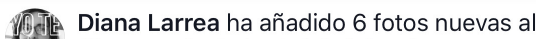
álbum Ende (mitad del siglo X). 2 de agosto de 2017 . 2

Tal día como hoy, pudo haber nacido en el norte de España a mediados del siglo $X$ una iluminadora de manuscritos Ilamada Ende. Ella es la... Ver más
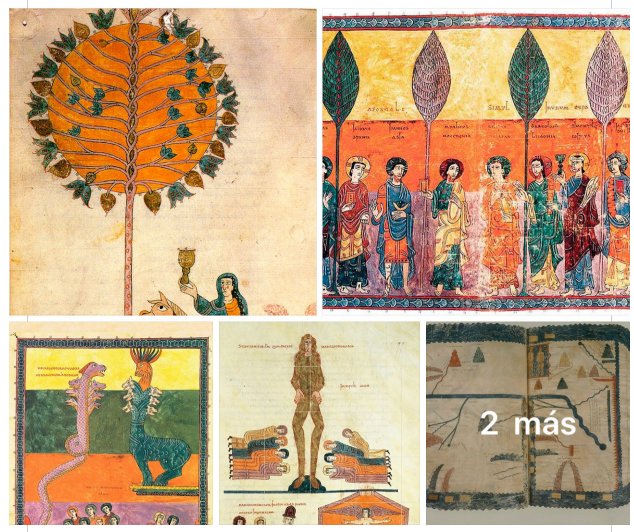

[ Añadir fotos o vídeos al álbum

Añadir más 


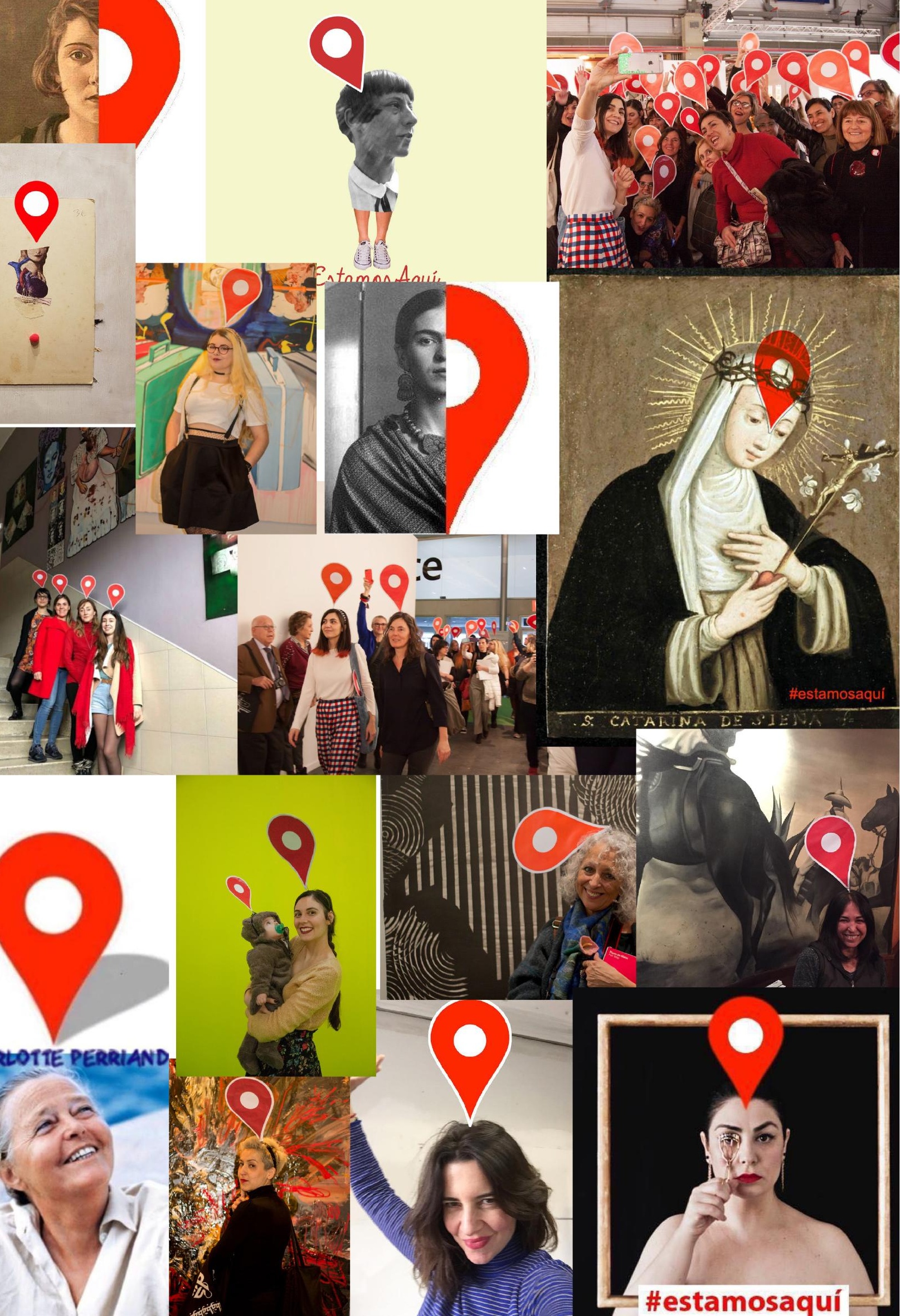


En todos los rincones del mundo se ha debatido en el campo teórico extensamente sobre la exclusión, la posibilidad de un arte femenino distinto del arte de los hombres, con importantes trabajos en torno a esos territorios estrictamente femeninos y muy especialmente en torno al cuerpo, al sexo y al género. El diálogo es rico y lleno de paradojas y fines que se anulan a sí mismos, como bien nos recuerda Carolyn Korsmeyer, autora de un libro emblemático: Gender and Aesthetics ${ }^{1}$. y a quien tenemos el honor de tener como autora invitada presentando este número de la revista con su texto: Efervescencias salvajes: una mirada retrospectiva al arte feminista, traducido y anotado por la profesora Rosa Fernández Gómez, de la Universidad de Málaga. En él, Korsmeyer, hace un repaso crítico por las aportaciones del feminismo a la Historia del Arte, desde Nochlin hasta la más reciente y polémica retirada de la obra prerrafaelista de John Waterhouse Hilas y las Ninfas, del Museo de Manchester. En su ensayo, la autora pone sobre la mesa preguntas fundamentales y anima a corregir el registro histórico en el que estamos insertas.

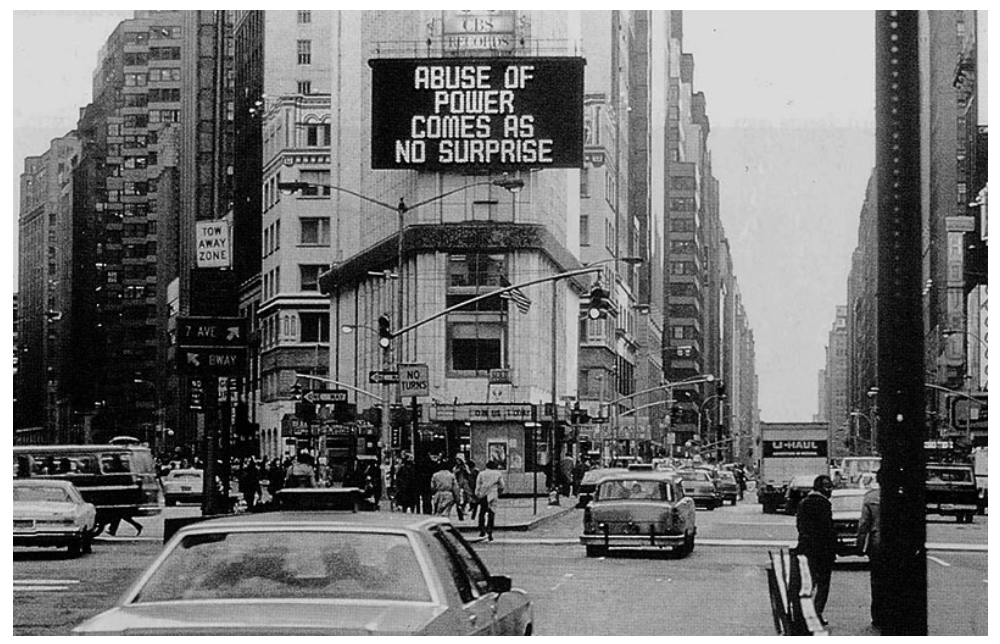

Jenny Holzer Abuse of Power Comes as No Surprise, New York, 1977.

Hay que decir, sin embargo, que este no es, ni mucho menos, un asunto de la contemporaneidad, el abuso que hace el poder de los débiles no es una novedad; y el hecho de que la supremacía esté en manos de hombres blancos también es conocido desde antiguo. El arte se ha hecho eco de ello desde el inicio de los movimientos feministas. La mítica obra de Jenny Holzer Abuse of Power Comes as No Surprise, que pertenece a su serie Truismos (Truisms), es una especie de aforismo de los que la artista se sirvió en aquella década de los 70 en que el feminismo empezaba su andadura en la Historia del Arte para remover la conciencia, y provocar al espectador a través del lenguaje, utilizado a la manera de los mensajes publicitarios en vallas, lugares emblemáticos y monumentos importantes. La artista intentaba despertar las conciencias respecto a grandes problemas sirviéndose de pequeñas llamadas de atención: haciendo referencia a lo que ella consideraba una necesaria reflexión a la vista de la inmersión del hombre en la sociedad de consumo; apareció en el cartel publicitario luminoso gigante que corona el edificio de Times Square y, para ello, la artista tuvo que apropiarse no solo de los dispositivos electrónicos de señalización, y de los lugares destinados a la publicidad, sino del propio espacio público y del poder de atraer 
la mirada de los viandantes sobre su obra. Este apropiacionismo, que coloca a la mujer artista en el lugar del poder y al ámbito de lo privado en el dominio de lo público, pone sobre el tablero muchas cuestiones importantes sobre las que se trata en este número de la revista. Desde entonces se ha publicado ampliamente, se han realizado importantes exposiciones, se han creado centros tan importantes como el Elizabeth A. Sackler Center for Feminist Art, albergado en el Brooklyn Museum de Nueva York y, o el museo de Arte de Mujeres de Washington.

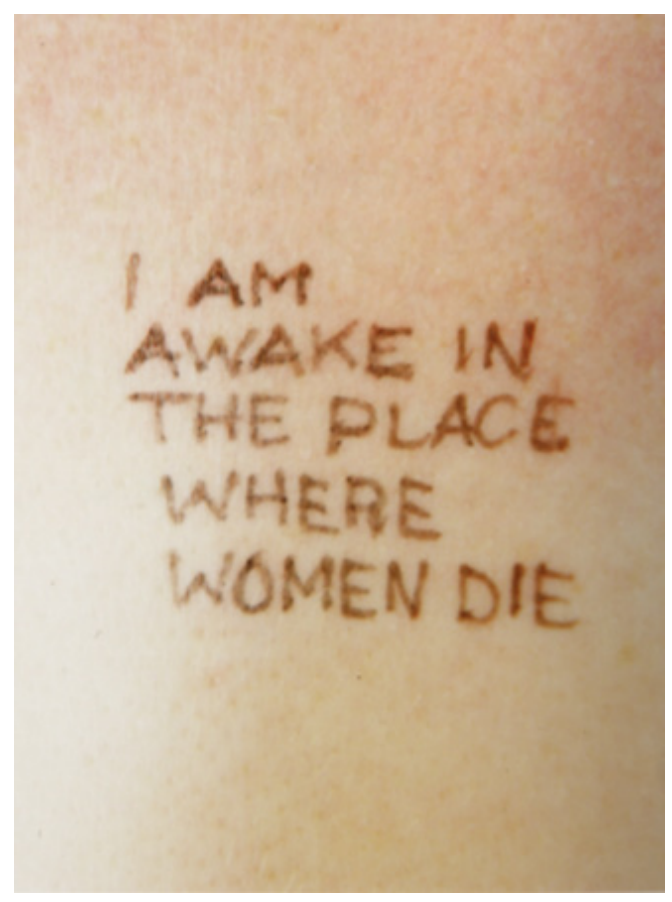

Jenny Holzer, Lustmord, 1993

Muy posiblemente, en aquel momento, muchos espectadores pasaron de largo ante las obras de Jenny Holzer sin fijarse en ellas y tuvieron que llegar los años 90 para que la artista volviera a un territorio que ya habían explorado mucho las feministas esencialistas y al que necesariamente vuelve una y otra vez toda reflexión sobre feminismo y sobre identidad: el cuerpo, y la memoria que queda sobre él. En su escalofriante trabajo Lustmord, de los años noventa, la artista nos recordaba haciendo alusión a los crímenes de la guerra de los Balcanes: "I am awake in the place where women die" (Estoy alerta allí donde las mujeres mueren), una frase que también anunció como cartel luminoso, pero que decidió tatuar en la piel de las personas que acudieron a sus performances, fijando, para siempre, ese compromiso que, como mujer, contraía con sus hermanas violadas, torturadas y asesinadas en el conflicto. Somos muchas las mujeres y hombres vinculadas al mundo del arte y de la visualidad que no podemos dejar de permanecer alerta ante la constante utilización del cuerpo femenino en los conflictos internacionales y también en nuestro entorno cotidiano, a la relación que existe entre cuerpo y poder, al debate constante que se plantea entre lo personal y lo político.

Sin duda alguna, en la ceremonia de la entrega de los Globos de Oro el discurso más escuchado fue el de Oprah Winfrey, pero quizá el más significativo desde el punto de vista del arte fue el de Meryl Streep que dio en el clavo planteando algu- 
nas de las cuestiones clave en estos asuntos: la cuestión del arte cuando se transforma en realidad, la misión del actor/artista de entrar en la vida de los demás y hacerles sentir diferentes, el arte como territorio para la libertad de expresión y, en definitiva, el arte como territorio para la libertad. Meryl Streep, que curiosamente había estudiado en Vassar, la universidad donde enseñó Linda Nochlin, acabó su discurso citando a la princesa Leia cuando decía "coge tu corazón roto y conviértelo en arte", una apelación a esa capacidad sanadora, reconstructora del arte y de la educación estética, quizá uno de los pocos recursos que nos queden por hacer habitable e igualitario el mundo.

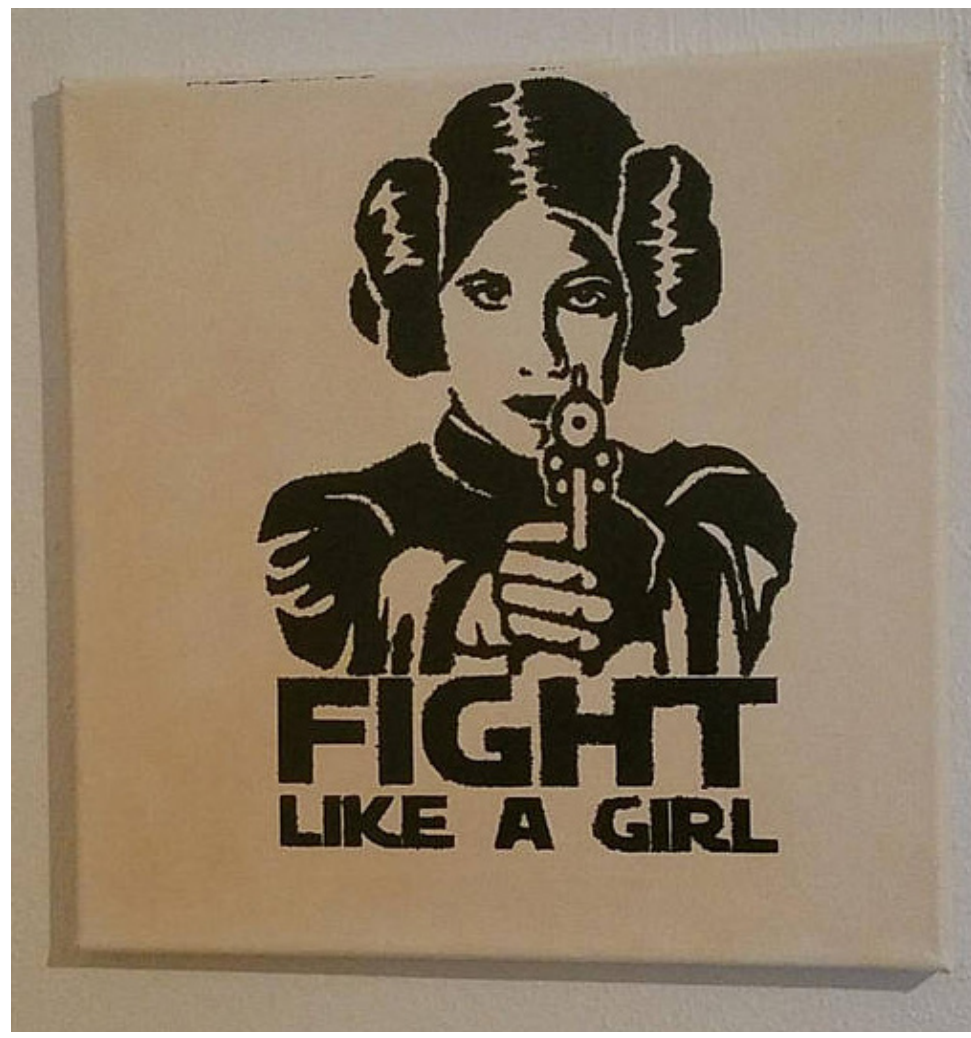

Eva Fernández del Campo Orcid 0000-0002-4125-0191 Directora de Anales de Historia del Arte Madrid, Julio de 2018 